\title{
CDISC SDTM Pharmacogenomics/Genetics Methods and Supporting Information Test Code Terminology
}

National Cancer Institute

\section{Source}

National Cancer Institute. CDISC SDTM Pharmacogenomics/Genetics Methods and

Supporting Information Test Code Terminology. NCI Thesaurus. Code C135010.

Terminology associated with the pharmacogenomics/genetics methods and supporting information test code codelist of the Clinical Data Interchange Standards Consortium (CDISC) Study Data Tabulation Model (SDTM). 